Article

\title{
Linking Phubbing Behavior to Self-Reported Attentional Failures and Media Multitasking
}

\author{
Kayla S. Sansevere *(D) and Nathan Ward \\ Department of Psychology, Tufts University, 490 Boston Ave, Medford, MA 02155, USA; nathan.ward@tufts.edu \\ * Correspondence: kayla.sansevere@tufts.edu
}

check for updates

Citation: Sansevere, K.S.; Ward, N Linking Phubbing Behavior to Self-Reported Attentional Failures and Media Multitasking. Future Internet 2021, 13, 100. https:// doi.org/10.3390/fi13040100

Academic Editor: Salvatore Carta

Received: 6 March 2021

Accepted: 12 April 2021

Published: 14 April 2021

Publisher's Note: MDPI stays neutral with regard to jurisdictional claims in published maps and institutional affiliations.

Copyright: (C) 2021 by the authors. Licensee MDPI, Basel, Switzerland. This article is an open access article distributed under the terms and conditions of the Creative Commons Attribution (CC BY) license (https:// creativecommons.org/licenses/by/ $4.0 /)$.

\begin{abstract}
Phubbing, or using a phone to snub another person, has been investigated through social and personality frameworks. Phubbing involves attending to and performing competing tasks, implying the involvement of attentional abilities. Yet, past research has not yet used a cognitive framework to establish a link between phubbing and attention. Using self-report data from a large online sample, we explored the associations between phubbing and everyday attentional failures. Phubbing was associated with difficulties in attentional shifting and distractibility, frequent attentional lapses, spontaneous and deliberate mind wandering, and attention-related cognitive errors. When examining these attention variables alongside several psychosocial and personality variables, attention-related cognitive errors acted as the biggest predictor of phubbing behavior. Phubbing was also positively correlated with media multitasking, which is a conceptually similar yet distinct technology use behavior. The results suggest that perceived everyday attentional failures are strongly associated with, and to an extent can predict, phubbing behavior, even more so than some social and personality variables. Technology has incorporated itself as a necessity, or at the very least a favored convenience, in most people's lives. Characterizing technology multitasking behaviors from a variety of frameworks can help us better understand who is engaging in these behaviors and why.
\end{abstract}

Keywords: phubbing; technoference; multitasking; attention; media multitasking

\section{Introduction \\ 1.1. Past Research}

Across the United States in 2019, nearly $81 \%$ of the total population owned a cell phone, $74 \%$ owned a desktop or laptop computer, and $52 \%$ owned a tablet [1]. In the same year, the average adult in the United States spent nearly 12 hours a day consuming media across these devices, which included but was not limited to watching television and movies, listening to music, browsing the internet, and playing video games [1]. Because the coronavirus disease 2019 pandemic has created a heightened reliance on the internet and technology [1], it is likely technology use and media consumption rates are much higher now than ever before. For many Americans, cell phones in particular are always present and turned on [2]. This has especially influenced social interactions. For instance, in a sample of over 3,000 adults in the United States in 2015,89\% reported that they used their phone at least once during their most recent social interaction despite the fact that $82 \%$ believed that phones can hurt a social interaction [2]. Though many Americans perceive technology use to be more harmful than helpful during social interactions, they still engage in such behavior. Thus, it is critical to understand how technology use behaviors are influenced by certain individual characteristics and can influence social experiences.

One technology use behavior gaining interest within recent years is technoference, or technology interference, an intrusion that typically occurs in social interactions [3-5]. A manifestation of technoference is phubbing, which occurs when an individual uses their phone to snub a conversational partner [6-9]. Because phubbing involves social interaction, 
it has most commonly been investigated in relation to psychosocial influences $[10,11]$. Situational characteristics, such as the setting of the interaction (e.g., on public transit, at the dinner table) can predict phubbing behavior [11]. Certain personality traits and psychological characteristics can further predict who engages in this technoference behavior. Phubbing behavior is negatively associated with conscientiousness [12] and self-control [6], and is positively associated with trait boredom [10], trait anxiety and neuroticism [13], state and trait fear of missing out $[6,7,13,14]$, as well as sensation seeking [14]. Other dispositional factors, such as gender and age, have also been found to be associated with phubbing behavior $[6,8,10,13,14]$.

While phubbing has been extensively investigated through social and personality frameworks, little is known about how this technoference behavior relates to cognition. This is surprising given the links between other phone use behaviors and cognition have been heavily explored [15-19]. Despite various social and personality researchers suggesting that phubbing is a multitasking behavior [10,20-22], phubbing has not yet been fully and directly investigated through a cognitive framework. It is possible that phubbing can be characterized as a multitasking behavior because it involves attending to, or at least attempting to attend to, competing sources of information (i.e., a phone and a conversational partner) and performing multiple tasks (i.e., using a phone while engaging in a social interaction with a conversational partner) by dividing or shifting attention (i.e., dual tasking or task switching) $[17,23,24]$. Although multitasking behaviors can be investigated through social and personality frameworks, they can further be understood through a cognitive framework, particularly with a focus on attention. The negative association between phubbing and self-control [6], which is an aspect of inhibitory control, suggests that individuals who phub may have difficulty directing and maintaining their attention toward tasks because they struggle to regulate their behavior. Difficulty in directing and maintaining attention could manifest in different ways in terms of everyday attentional failures. For instance, individuals who frequently phub may also exhibit less attentional control and experience persistent instances of attentional lapses, mind wandering, and cognitive errors as a result of these failures of attention. By evaluating phubbing with a cognitive framework focused on attention and multitasking in particular, we can build more comprehensive profiles of those who are more likely to engage in this behavior.

Phubbing also seems very similar to another technology use and multitasking behavior: media multitasking, which involves concurrently using or switching between multiple media activities (e.g., texting while watching TV) $[25,26]$. Both phubbing and media multitasking involve paying attention to a media activity either during a social interaction or alongside another media activity. In addition to being conceptually related, these two behaviors also share the same directional relationships across multiple self-reported psychosocial, psychological, and personality constructs, including sensation seeking [14,27-29], fear of missing out [6,7,13,29], general anxiety [13,30], and neuroticism [13,31]. Moreover, media multitasking has been extensively investigated through a cognitive framework. Frequent media multitaskers report impaired abilities to monitor and switch tasks [32-34], though some studies have found no association between media multitasking, perceived distractibility, and difficulties in shifting attention [35]. Frequent media multitaskers have also reported more frequent occurrences of mind wandering [35,36], attentional lapses [35], and cognitive failures as a result of such attentional lapses [35,37], as well as less overall mindful attentional awareness $[36,37]$. Because phubbing and media multitasking appear to be very similar, it is plausible to use the results from media multitasking to infer what self-reported attentional abilities may be implicated in phubbing behavior. If phubbing were to involve the same attentional abilities as media multitasking, this could suggest a common or shared underlying mechanism among the two behaviors. This would also be supported if the same people who frequently engage in phubbing behavior are also likely to engage in media multitasking behavior, implying that these two behaviors are directly related. Investigating the indirect and direct links between phubbing and media 
multitasking can help us better characterize both behaviors and can contribute to the primary aim of our study.

\subsection{Current Research}

The primary aim of the current study was to investigate if and how a variety of selfreported everyday attentional failures, including attentional switching and distractibility, deliberate and spontaneous mind wandering, attentional lapses, and attention-related cognitive errors, were associated with phubbing behavior. As mentioned above, individuals who phub may also struggle with directing and maintaining their attention, which would suggest positive associations between phubbing behavior and many of our self-reported cognitive measures, including mind wandering, attentional lapses, and attention-related cognitive errors. If several of these everyday attentional failures were correlated with phubbing behavior, we were particularly interested in which could best predict this behavior, both among this selection of cognitive abilities and when accounting for select psychosocial and personality constructs.

Our secondary aim was to explore the indirect and direct associations between phubbing behavior and media multitasking. We explored the indirect relationship between these two behaviors by investigating if they shared the same directional relationship among various measures of everyday attentional failures. We investigated the direct relationship between these two behaviors by testing if they were correlated with one another. If phubbing was positively associated with media multitasking, this would suggest that individuals who frequently engage in phubbing behavior also frequently engage in media multitasking, which would fill a gap in the literature between these two technology use behaviors.

Our study was one of the first to measure phubbing behavior and cognitive functioning in the same participants. It was plausible that we would observe positive associations between phubbing behavior and attentional failures, but it could have also been the case that there would be no associations between these measures or that there would be negative associations. Given the lack of prior research with these specific measures, our aims were thus more exploratory rather than confirmatory. Furthermore, we leveraged the link between another potentially related technology use behavior (i.e., media multitasking) and self-reported cognitive function to better understand cognitive function and phubbing behavior. However, prior findings between media multitasking and self-reported cognitive functioning have been mixed [32-37], making strong confirmatory predictions somewhat difficult. That said, there is a growing need to understand how technology use behaviors both can influence and are influenced by our cognition. By exploring and establishing some of the first cognitive correlates and predictors of phubbing behavior, we can further characterize the relationship between humans and technology.

\section{Materials and Methods}

Prior to data collection, we pre-registered our plans, materials, and code on the Open Science Framework. In addition, our de-identified data are also available: https: / / osf.io/7kgnd/ (accessed on 12 April 2021).

\subsection{Participants}

We recruited Amazon Mechanical Turk (MTurk) workers located in the United States with high reputations (i.e., $\geq 500$ approved HITs with $\geq 95 \%$ approval rating). We used these criteria because Amazon MTurk workers with high reputations are likelier to produce higher-quality data than those with low reputations [38]. Our target sample size was 500 participants based both on prior studies as well as recommendations for correlations [39] and standard multiple regression [40]. A total of 776 Amazon MTurk workers enrolled in our study, and $280 \mathrm{did}$ not complete the entire study because they did not pass an embedded attention check block. Of the 496 Amazon MTurk workers who completed the entire study, we excluded participants from data analysis if they did not pass one or 
both attention check items that we disguised within two separate questionnaire items ( $n=21)$, completed the entire study in less than 10 minutes $(n=28)$, or indicated that they answered randomly at some point during any of the study $(n=74)$. Thus, 373 participants (age $M=37.40$ years, $S D=9.94$ years; $38 \%$ women; $16 \%$ Hispanic, Latino, or Spanish origin; $79 \%$ White) were included in data analysis. All participants were compensated a flat rate of $\$ 5.43$.

\subsection{Measures}

\subsubsection{Generic Scale of Phubbing (GSP)}

The GSP [7] is a 15-item questionnaire that measures the degree to which individuals engage in phubbing behavior. The survey includes four subscales: nomophobia, interpersonal conflict, self-isolation, and problem acknowledgement. Examples of items include "I cannot stand leaving my phone alone" and "I pay attention to my phone for longer than I intend to do so". Items are responded to using a seven-point Likert-type scale, ranging from never (1) to always (7). Survey scores are calculated by summing all item responses, with scores ranging from 15 to 105. A higher score reflects greater engagement in phubbing behavior.

\subsubsection{Attentional Control: Shifting (AC-S) and Distraction (AC-D)}

The AC-S is a four-item questionnaire that measures one's ability to shift attention between tasks, and the AC-D is a four-item questionnaire that measures an individual's degree of distractibility [41,42]. Examples of items on the AC-S include "I am slow to switch from one task to another" and "It is difficult for me to alternate between two different tasks", while examples of items on the AC-D are "I have difficulty concentrating when there is music in the room around me" and "When I am working hard on something, I still get distracted by events around me". Responses for both scales are collected with a five-point Likert-type scale ranging from almost never (1) to always (5). Scores for the AC-S and AC-D are calculated by computing the average across each of the survey's four items. Higher scores on the AC-S reflecting greater difficulty switching attention between tasks and higher scores on the AC-D reflecting frequent distractibility.

\subsubsection{Mind Wandering: Deliberate (MW-D) and Spontaneous (MW-S)}

The MW-D is a four-item questionnaire that measures tendency to deliberately mind wander, and the MW-S consists of four items that assess the tendency to spontaneously mind wander [41]. The MW-D questionnaire includes items such as "I allow my thoughts to wander on purpose" and "I enjoy mind wandering", and examples of items on MW-S questionnaire include "I find my thoughts wandering spontaneously" and "When I mind wander my thoughts tend to be pulled from topic to topic". For the MW-D, Carriere and colleagues [41] originally collected responses using a seven-point Likert-type scale ranging from rarely (1) to a lot (7) for items 1, 2, and 4, and ranging from not at all true (1) to very true (7) for item 3. For the MW-S, Carriere and colleagues [41] scored responses using a seven-point Likert-type scale ranging from rarely (1) to a lot (7) for items 1, 2, and 4, and ranging from almost never (1) to almost always (7) for item 3. In the current study, we modified the responses for MW-D and MW-S to a seven-point Likert-type scale ranging from never (1) to always (7). The scores for the MW-D and MW-S are calculated by computing the average across each of the survey's four items. Higher scores on the MW-D reflecting greater tendencies to deliberately mind wander and higher scores on the MW-S reflecting greater tendencies to spontaneously mind wander.

\subsubsection{Mindful Attention Awareness Scale-Lapses Only (MAAS-LO)}

The MAAS-LO [43] is a 12-item questionnaire derived from the 15-item Mindful Attention Awareness Scale (MAAS) [44]. The MAAS-LO assesses the frequency with which individuals experience attentional lapses in everyday situations. The MAAS-LO includes items such as "I find myself doing things without paying attention" and "I find it difficult 
to stay focused on what's happening in the present". Responses are collected using a six-point Likert-type scale ranging from almost never (1) to almost always (6). Survey scores are calculated by summing all item responses, and scores range from 12 to 72 . A higher score on the MAAS-LO represents a higher frequency of attention lapses.

\subsubsection{Attention-Related Cognitive Errors Scale (ARCES)}

The ARCES $[43,45]$ is a 12 -item questionnaire that measures how frequently individuals make minor mistakes as a result of absent-mindedness. Some items from the ARCES are "I make mistakes because I am doing one thing and thinking about another" and "I have absent-mindedly placed things in unintentional locations". Responses are collected using a five-point Likert-type scale that ranges from never (1) to very often (5). Survey scores are calculated by summing all item responses and can range from 12 to 60 . Higher scores reflect a greater frequency of cognitive failures as a result of absentmindedness.

\subsubsection{Media Multitasking Index-Version 2 (MMI-2)}

The MMI-2 [46,47] is a modified version of the Media Multitasking Index (MMI) [25] and measures an individual's daily tendency to media multitask across 10 media activities. The media activities include (1) face-to-face communication; (2) using print media; (3) texting, instant messaging, or emailing; (4) using social sites; (5) using non-social textoriented sites; (6) talking on the phone or video chatting; (7) listening to music; (8) watching television and movies; (9) playing video games or online games; and (10) doing homework, studying, or writing papers. Individuals report how many hours they spend on an average day engaging with each media activity. Following this, individuals indicate the extent to which they simultaneously use and engage with a second media activity of the same type (e.g., playing two video games) as well as different type (e.g., playing video games while listening to music) using a four-point Likert-type scale with the following response categories and percentages: never (0), a little of the time (0.33), some of the time (0.66), and most of the time (1). MMI-2 scores can range from 0 to 10 and were calculated using the original MMI formula [25]. Higher scores indicate greater engagement in media multitasking on an average day.

\subsubsection{Short Media Multitasking Measure (MMM-S)}

The MMM-S [48] is a modified version of the MMI [25] that was originally designed to assess media multitasking in Dutch adolescents and teenagers. In this original sample, scores on the MMM-S were strongly, significantly correlated with scores on the MMI $(r=0.82, p<0.001)$ [48]. The MMM-S contains nine items and measures media multitasking across four of the most frequently engaged with media activities: watching television, using social networking sites, sending messages via phone or computer, and listening to music. Participants indicate the extent to which they simultaneously use and engage with two different media activities (e.g., watching TV and listening to music) using a four-point Likert-type scale ranging from never (1) to very often (4). The MMM-S score is calculated by taking the average across the nine items. A higher score indicates a higher frequency to engage in media multitasking on an average day.

\subsubsection{Media Use}

The media use questionnaire [48] asks participants to indicate the frequency to which they engage in three of the four media activities of the MMM-S (watching television, using social networking sites, and sending messages via phone or computer) in an average day. Answers are given using eight-point Likert-type scale ranging from not at all (1) to more than 5 hours (8) was used. The media use score is calculated by finding the average across the three items. A higher score indicates a higher media use frequency on an average day. 


\subsubsection{Barratt Impulsiveness Scale (BIS-11)}

The BIS-11 [49] is a 30-item questionnaire measuring the personality and behavioral construct of impulsiveness. The BIS-11 includes three primary order factors, including attentional impulsiveness, motor impulsiveness, and non-planning impulsiveness, and six secondary order factors. The two secondary order factors that map onto the first primary order factor of attentional impulsiveness are attention and cognitive instability. The two secondary order factors that map onto the second primary order factor of motor impulsiveness are motor and perseverance. Finally, the remaining two secondary order factors that map onto the third primary order factor of non-planning impulsiveness are self-control and cognitive complexity. Example items on the BIS-11 include "I plan tasks carefully" and "I am self-controlled". Responses are provided using a four-point Likerttype scale that ranges from rarely/never (1) to almost always/always (4). Survey scores are calculated by summing all item responses and can range from 30 to 120. A higher score indicates a higher level of impulsiveness.

\subsubsection{Short Self-Regulation Questionnaire (SSRQ)}

The SSRQ [50] is a 31-item questionnaire designed to assess self-regulation capacity and is based on the Self-Regulation Questionnaire (SRQ) [51]. Examples of items include "I have a lot of willpower" and "As soon as I see a problem or challenge, I start looking for possible solutions". Participants indicate the extent to which they agree with each item using a five-point Likert-type scale ranging from strongly disagree (1) to strongly agree (5). Survey scores are calculated by summing all item responses and can range from 31 to 155 . Higher scores on the SSRQ indicate greater degree of self-regulation.

\subsubsection{Social Connectedness Scale (SCS)}

The SCS [52] is an eight-item questionnaire measuring three aspects of belongingness: connectedness, affiliation, and companionship. The SCS includes items such as "I feel disconnected from the world around me" and "Even around people I know, I do not feel that I really belong". Responses are given using a six-point Likert-type scale that ranges from agree (1) to disagree (6). Survey scores are calculated by summing all item responses and range from 8 to 48 . Higher scores reflect a greater sense of social connectedness and belongingness.

\subsection{Procedure}

This study was approved by the Tufts University Institutional Review Board (\#00000926) and was conducted in accordance with the ethical standards as laid down in the 1964 Declaration of Helsinki and its later amendments or comparable ethical standards. All subjects gave their informed consent for inclusion before they participated in the study. After providing informed consent, participants answered demographic and media use questions. Participants then completed the MMI-2 and MMM-S in a counterbalanced order. Next, participants encountered an attention check block that directed for a specific answer for the next several questions at the end of a longer text [53]. Participants who did not respond to all of the questions on the page with the instructed answer were directed to the end of the survey and asked to return, rather than submit, the HIT on Amazon MTurk. If participants answered all items in this attention check block with the instructed answer, they completed the following surveys in a randomized order: GSP, GSBP, AC-S, AC-D, MW-D, MW-S, MAAS-LO, ARCES, BIS-11, SSRQ, and SCS. Participants then answered a compliance item that asked whether they randomly responded at any point during any of the surveys. Afterward, participants were thanked, debriefed, and compensated.

\section{Results}

We used $\mathrm{R}$ (version 4.0.2) for data processing and jamovi (version 1.2.27.0) for data analysis. Given our large sample size and the overpowered basis of the Shapiro-Wilk test, we visually inspected Q-Q plots to determine normal distribution [54]. The the- 
oretical quantiles conformed fairly well to the standardized residuals, suggesting that deviations were not likely to be consequential. For both regression models, the variance inflation factors (VIFs) were all less than 5, indicating that while the regressors were moderately correlated, regression coefficients were unlikely to be poorly estimated due to multicollinearity [54]. The alpha threshold was 0.05 for statistical significance and all statistical models were two tailed. Descriptive statistics for each questionnaire are presented in Table 1.

Table 1. Summary of means, standard deviations, ranges, skewness, kurtosis, and Cronbach's alphas for survey measures $(N=373)$.

\begin{tabular}{cccccc}
\hline & Mean (SE) & Min-Max & Skewness & Kurtosis & $\alpha$ \\
\hline GSP & $48.90(1.21)$ & $15-99$ & 0.17 & -1.14 & 0.97 \\
AC-S & $2.70(0.05)$ & $1-5$ & -0.07 & -0.86 & 0.86 \\
AC-D & $2.86(0.05)$ & $1-5$ & -0.25 & -0.90 & 0.85 \\
MW-D & $4.16(0.07)$ & $1-7$ & -0.19 & -0.66 & 0.92 \\
MW-S & $3.90(0.07)$ & $1-7$ & -0.09 & -0.81 & 0.91 \\
MAAS-LO & $38.70(0.72)$ & $12-72$ & -0.09 & -0.89 & 0.94 \\
ARCES & $33.40(0.50)$ & $12-54$ & 0.07 & -0.71 & 0.93 \\
MMI-2 & $4.05(0.12)$ & $0.18-10$ & 0.36 & -1.01 & - \\
MMM-S & $2.47(0.04)$ & $1-4$ & 0.01 & -0.78 & 0.91 \\
Media Use & $4.49(0.07)$ & $1.67-8$ & 0.40 & -0.63 & - \\
BIS-11 & $61.90(0.67)$ & $35-88$ & -0.12 & -1.06 & 0.89 \\
SSRQ & $114.00(1.05)$ & $59-155$ & 0.24 & -0.75 & 0.94 \\
SCS & $32.00(0.59)$ & $8-48$ & -0.11 & -1.15 & 0.97
\end{tabular}

Note. GSP = Generic Scale of Phubbing; AC-S = Attentional Control: Shifting; AC-D = Attentional Control: Distraction; MW-D = Mind Wandering: Deliberate; MW-S = Mind Wandering: Spontaneous; MAAS-LO = Mindful Attention Awareness Scale-Lapses Only; ARCES = Attention-Related Cognitive Errors Scale; MMI-2 = Media Multitasking Index-Version 2; MMM-S = Short Media Multitasking Measure; BIS-11 = Barratt Impulsiveness Scale; SSRQ = Short Self-Regulation Questionnaire; SCS = Social Connectedness Scale.

\subsection{Correlations between Phubbing Behavior and Everyday Attentional Failures}

To address the primary aim of the current study, we examined Pearson correlation coefficients between scores on the primary measure of phubbing behavior, which was the GSP, and scores on measures of self-reported everyday attentional failures, which included the AC-S, AC-D, MW-D, MW-S, MAAS-LO, and ARCES. To reiterate, higher scores on each of these measures corresponds to greater attentional difficulties and failures within the respective attentional domain. GSP scores were significantly and positively correlated with scores on the AC-S, AC-D, MW-D, MW-S, ARCES, and MAAS-LO, rs = 0.45-0.72, ps $<0.001$ (see Table 2). The strength of the Pearson correlation coefficients between the GSP and measures of self-reported everyday attentional failures were, in ascending order, as follows: AC-D, MW-D, AC-S, MAAS-LO, MW-S, and ARCES.

\subsection{Correlations between Phubbing Behavior, Demographics, and Select Psychosocial and Personality Variables}

To account for other potential variables related to phubbing behavior, we examined other dispositional factors, including demographics as well as several psychosocial and personality variables. GSP scores were significantly and negatively correlated with age, $r(371)=-0.27, p<0.001$. There was no significant effect of gender on phubbing behavior, $t(371)=-1.25, p=0.211$, therefore we did not analyze this variable any further. In terms of specific psychosocial and personality measures, we examined associations among impulsivity, self-regulation, and social connectedness with phubbing behavior. There was a significant positive correlation between GSP scores and BIS-11 scores, $r(371)=0.63$, $p<0.001$. Additionally, there were significant negative associations between GSP scores with SSRQ scores, $r(371)=-0.60, p<0.001$, and SCS scores, $r(371)=-0.47, p<0.001$. Thus, the strength of the significant associations between the GSP and demographic, psychosocial, and personality measures were, in ascending order, as follows: age, SCS, SSRQ, and BIS-11. 


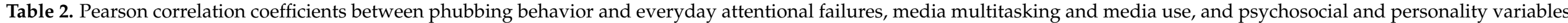
$(N=373)$.

\begin{tabular}{|c|c|c|c|c|c|c|c|c|c|c|c|c|}
\hline & GSP & AC-S & AC-D & MW-D & MW-S & MAAS-LO & ARCES & MMI-2 & MMM-S & Media Use & BIS-11 & SSRQ \\
\hline AC-S & $0.63^{* * *}$ & - & & & & & & & & & & \\
\hline AC-D & $0.45^{* * *}$ & $0.64^{* * *}$ & - & & & & & & & & & \\
\hline MW-D & $0.62^{* * *}$ & $0.51^{* * *}$ & $0.43^{* * *}$ & - & & & & & & & & \\
\hline MW-S & $0.69^{* * *}$ & $0.63^{* * *}$ & $0.58^{* * *}$ & $0.80^{* * *}$ & - & & & & & & & \\
\hline MAAS-LO & $0.68^{* * *}$ & $0.69^{* * *}$ & $0.58^{* * *}$ & $0.60^{* * *}$ & $0.72 * * *$ & - & & & & & & \\
\hline ARCES & $0.72^{* * *}$ & $0.69^{* * *}$ & $0.55^{* * *}$ & $0.60^{* * *}$ & $0.71^{* * *}$ & $0.80^{* * *}$ & - & & & & & \\
\hline MMI-2 & $0.78^{* * *}$ & $0.51^{* * *}$ & $0.27^{* * *}$ & $0.53^{* * *}$ & $0.58^{* * *}$ & $0.56^{* * *}$ & $0.60^{* * *}$ & - & & & & \\
\hline MMM-S & $0.68^{* * *}$ & $0.35^{* * *}$ & $0.18^{* * *}$ & $0.52^{* * *}$ & 0.52 *** & $0.50^{* * *}$ & $0.52^{* * *}$ & $0.81^{* * *}$ & - & & & \\
\hline Media Use & $0.60^{* * *}$ & $0.31^{* * *}$ & $0.12 *$ & $0.41^{* * *}$ & $0.39 * * *$ & $0.36^{* * *}$ & $0.42^{* * *}$ & $0.67^{* * *}$ & $0.66^{* * *}$ & - & & \\
\hline BIS-11 & $0.63^{* * *}$ & $0.61^{* * *}$ & $0.53^{* * *}$ & $0.53^{* * *}$ & $0.67^{* * *}$ & $0.70^{* * *}$ & $0.66^{* * *}$ & $0.56^{* * *}$ & $0.47^{* * *}$ & $0.31^{* * *}$ & - & \\
\hline SSRQ & $-0.60^{* * *}$ & $-0.63^{* * *}$ & $-0.49^{* * *}$ & $-0.45^{* * *}$ & $-0.62 * * *$ & $-0.68^{* * *}$ & $-0.60 * * *$ & $-0.46^{* * *}$ & $-0.35^{* * *}$ & $-0.27 * * *$ & $-0.79 * * *$ & - \\
\hline SCS & $-0.47^{* * *}$ & $-0.57^{* * *}$ & $-0.48^{* * *}$ & $-0.37^{* * *}$ & $-0.55^{* * *}$ & $-0.59^{* * *}$ & $-0.52^{* * *}$ & $-0.35^{* * *}$ & $-0.22^{* * *}$ & $-0.16^{* *}$ & $-0.58^{* * *}$ & $0.68^{* * * *}$ \\
\hline
\end{tabular}

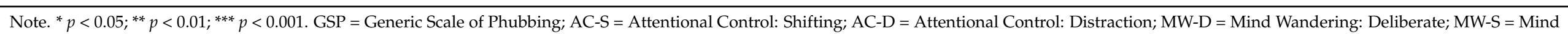

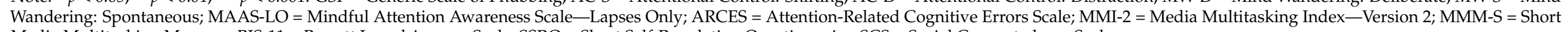
Media Multitasking Measure; BIS-11 = Barratt Impulsiveness Scale; SSRQ = Short Self-Regulation Questionnaire; SCS = Social Connectedness Scale . 


\subsection{Correlations between Phubbing Behavior and Media Multitasking}

The secondary aim of this study was to explore the indirect and direct associations between phubbing and media multitasking. We first explored the indirect relationship between phubbing and media multitasking by investigating if these two behaviors shared the same directional relationship among various measures of everyday attentional failures. Scores on the GSP, MMI-2, and MMM-S shared the same significant, positive directional associations among scores on the ARCES, MW-S, MAAS-LO, AC-S, MW-D, and AC-D, $r \mathrm{~s} 0.18-0.72, p s<0.001$ (see Table 2). These findings support an interpretation that there is a shared or underlying mechanism linking phubbing and media multitasking.

We also explored the direct relationship between phubbing and media multitasking by examining if these two variables were correlated with one another, in addition to exploring how phubbing was associated with general media use frequency. GSP scores were significantly and positively associated with scores on the MMI-2, MMM-S, and media use questionnaire, $r s=0.60-0.78, p s<0.001$ (see Table 2). It is also worth noting that there was also a significant positive correlation between MMI-2 scores and MMM-S scores, $r(371)=0.81, p<0.001$, which suggests that the MMM-S is a shorter and viable alternative for the MMI-2 in an adult sample from the United States. The strength of the associations between the phubbing behavior and media multitasking, media use, and multitasking preference was, in ascending order, as follows: media use, MMM-S, and MMI-2.

\subsection{Initial Regression Model of Everyday Attentional Failures Predicting Phubbing Behavior}

Because all of the everyday attentional failures were correlated with phubbing, we investigated which of these domains was most predictive of this behavior. We used standard multiple regression, rather than hierarchical or statistical regression, because this method provides the most conservative assessment of the unique contribution of each predictor variable on the outcome variable [54]. In an initial regression model, GSP scores were predicted using scores on ARCES, MW-S, MAAS-LO, AC-S, MW-D, and AC-D. This initial regression model allowed us to isolate the extent to which everyday attentional failures can predict phubbing behavior. The overall regression was statistically significant, and a large amount of the variance in GSP scores were explained by the attention measures, $R=0.78, R^{2}=0.61$, adjusted $R^{2}=0.61, F(6,366)=96.80, p<0.001$.

To assess the unique contribution of each predictor, the $t$ ratios for the individual regression slopes were examined. All six predictors significantly predicted GSP scores, which in included the MAAS-LO, AC-D, MW-D, MW-S, AC-S, and ARCES, ts $=-2.10-5.11$, $p s<0.05$ (see Table 3). Specifically, higher scores on the ARCES, AC-S, MW-S, MW-D, and MAAS-LO predicted higher scores on the GSP, respectively. Interestingly, lower scores on the AC-D, which indicates less distractibility, predicted higher scores on the GSP. Overall, these results imply that, at least among this sample, a higher frequency of everyday attentional failures, excluding distractibility, predicted engagement in phubbing behavior. In particular, experiencing a greater frequency of cognitive failures as a result of absentmindedness was most likely to predict phubbing behavior.

Table 3. Summary of initial standard multiple regression analysis for attentional predictors of phubbing behavior $(N=373)$.

\begin{tabular}{|c|c|c|c|c|c|}
\hline Predictor & Estimate & SE & $t$ & $p$ & Stand. Estimate \\
\hline Intercept & -13.40 & 3.08 & -4.34 & $<0.001$ & - \\
\hline ARCES & 0.73 & 0.14 & 5.11 & $<0.001$ & 0.30 \\
\hline AC-S & 4.45 & 1.24 & 3.59 & $<0.001$ & 0.19 \\
\hline MW-S & 3.55 & 1.09 & 3.27 & 0.001 & 0.21 \\
\hline MW-D & 2.47 & 0.94 & 2.63 & 0.009 & 0.14 \\
\hline AC-D & -2.24 & 1.07 & -2.10 & 0.037 & -0.09 \\
\hline MAAS-LO & 0.21 & 0.10 & 2.03 & 0.043 & 0.12 \\
\hline
\end{tabular}

Note. $R=0.78 ; R^{2}=0.61$; Adjusted $R^{2}=0.61 ; F(6,366)=96.80, p<0.001$. Estimates represent unstandardized regression coefficients. ARCES = Attention-Related Cognitive Errors Scale; AC-S = Attentional Control: Shifting; MW-S = Mind Wandering: Spontaneous; MW-D = Mind Wandering: Deliberate; AC-D = Attentional Control: Distraction; MAAS-LO: Mindful Attention Awareness ScaleLapses Only. 


\subsection{Expanded Regression Model of Everyday Attentional Failures, Demographics, and Select Psychosocial and Personality Variables Predicting Phubbing Behavior}

In an effort to better account for the variance in phubbing behavior scores, we repeated the standard multiple regression with the six a priori attention predictors to include the significant demographic, psychosocial, and personality correlates of GSP scores. These variables included age, BIS-11 scores, SSRQ scores, and SCS scores. We did not include media use frequency as a covariate in this expanded regression model because this measure was designed to accompany the MMM-S, and for our purposes, we were not interested in predicting phubbing behavior with media multitasking. When we introduced these additional potential predictors of phubbing behavior to this expanded regression model, it remained statistically significant, $R=0.79, R^{2}=0.63$, adjusted $R^{2}=0.62, F(10,362)=61.30$, $p<0.001$. Compared to the initial regression model, the accounted variance in phubbing behavior scores increased from $61 \%$ to approximately $63 \%$.

To assess the unique contribution of each predictor, the $t$ ratios for the individual regression slopes were examined. In this expanded regression model, only four of the 10 predictors were significantly predictive of GSP scores (see Table 4). In ascending order of contribution, these significant predictors included the MW-S, MW-D, AC-S, and ARCES, $t \mathrm{~s}=2.41-4.67, \mathrm{ps}<0.05$. Particularly in this expanded regression model, scores on AC-D and MAAS-LO did not significantly predict GSP scores as they did in the initial regression model, $p s>0.05$. The newly introduced demographic, psychosocial, and personality variables, which included age, and scores on the SSRQ, BIS-11, and SCS, did not significantly predict GSP scores in this expanded regression model, $p \mathrm{~s}>0.05$. Taken together, these results suggest that when everyday attentional failures are examined alongside select demographic, psychosocial, and personality variables to predict phubbing behavior, only certain everyday attentional failures (i.e., attention-related cognitive errors, switching attentional control, deliberate and spontaneous mind wandering) will predict engagement in phubbing behavior. At least among this sample, this could imply that these particular everyday attentional failures can predict engagement in phubbing behavior more so than the included demographic, psychosocial, and personality variables.

Table 4. Summary of expanded standard multiple regression analysis for attentional, psychosocial, personality, and demographic predictors of phubbing behavior $(N=373)$.

\begin{tabular}{|c|c|c|c|c|c|}
\hline Predictor & Estimate & SE & $t$ & $p$ & Stand. Estimate \\
\hline Intercept & 4.07 & 13.24 & 0.31 & 0.759 & - \\
\hline ARCES & 0.67 & 0.14 & 4.67 & $<0.001$ & 0.28 \\
\hline AC-S & 3.89 & 1.27 & 3.07 & 0.002 & 0.16 \\
\hline MW-D & 2.63 & 0.94 & 2.80 & 0.005 & 0.15 \\
\hline MW-S & 2.70 & 1.12 & 2.41 & 0.016 & 0.16 \\
\hline SSRQ & -0.13 & 0.07 & -1.86 & 0.064 & -0.11 \\
\hline $\mathrm{AC}-\mathrm{D}$ & -1.93 & 1.08 & -1.79 & 0.074 & -0.08 \\
\hline Age & -0.14 & 0.08 & -1.79 & 0.074 & -0.06 \\
\hline BIS-11 & 0.14 & 0.11 & 1.33 & 0.185 & 0.08 \\
\hline SCS & 0.10 & 0.10 & 1.03 & 0.304 & 0.05 \\
\hline MAAS-LO & 0.11 & 0.11 & 1.03 & 0.306 & 0.06 \\
\hline
\end{tabular}

Note. $R=0.79 ; R^{2}=0.63$; Adjusted $R^{2}=0.62 ; F(10,362)=61.30, p<0.001$. Estimates represent unstandardized regression coefficients. ARCES = Attention-Related Cognitive Errors Scale; AC-S = Attentional Control: Shifting; MW-D = Mind Wandering: Deliberate; MW-S = Mind Wandering: Spontaneous; SSRQ = Short Self-Regulation Questionnaire; AC-D = Attentional Control: Distraction; BIS-11 = Barratt Impulsiveness Scale; SCS = Social Connectedness Scale; MAAS-LO = Mindful Attention Awareness Scale-Lapses Only.

\section{Discussion}

The primary aim of the current study was to use self-report data to explore the relationships between phubbing behavior and everyday attentional abilities. To accomplish this, we first examined the associations between phubbing behavior, as measured by the GSP, and self-reported everyday attentional failures, as measured with the AC-S, AC-D, MW-D, MW-S, MAAS-LO, and ARCES. Having a robust set of validated measures allowed 
us to explore and pin down which of the most common everyday attentional abilities were implicated in phubbing behavior. Attention-related cognitive errors, spontaneous and deliberate mind wandering, difficulties with attentional shifting and distractibility, and lapses in attention were all positively and significantly correlated with phubbing behavior. In other words, individuals who reported more engagement in phubbing behavior also reported a greater frequency of difficulties across a variety of everyday attentional abilities. Intuitively, it makes sense that these various domains of attention were associated with phubbing behavior, as this technoference behavior implies that individuals are shifting or dividing their attention across various competing sources of information. Yet, our study provided some of the first empirical evidence to support this purported connection. Using a cognitive framework to explore the attentional correlates of phubbing behavior complements prior research that has primarily focused on social and personality constructs, and ultimately creates a more wholistic profile of the type of person who is most likely to engage in this behavior.

To better understand the relationship between phubbing and individual differences more broadly, we also explored if other select dispositional characteristics, including demographics and psychosocial and personality variables, were associated with phubbing behavior. Aligning with past research $[8,9,14]$, we found a significant negative association between phubbing and age, suggesting that younger adults tend to phub more than older adults. However, we did not find gender differences in phubbing behavior. This conflicts with past research $[6,8,10,13]$, which found that women report engagement in phubbing behavior more than men. Most of the studies that found a gender effect for phubbing behavior had recruited more women than men [6,8], though one study recruited more women and found no gender effect [14]. Approximately 38\% of the 373 participants in our study identified as women. One potential explanation for the difference between the current findings and past findings on gender and phubbing could be due to an unequal gender ratio. Future studies should take this consideration into account if they wish to better clarify the relationship between gender and phubbing.

We also compared correlations between scores on the GSP with scores on psychosocial and personality measures, which included the BIS-11, SSRQ, and SCS. Individuals that would describe themselves as more impulsive, lacking in self-regulation, and feeling less connected to and belongingness with others also reported more experiences of phubbing behavior. Past research has found phubbing to be negatively associated with social connectedness [7], and while a myriad of psychosocial and personality variables has been investigated alongside phubbing behavior, it has not yet been explored how this behavior relates to impulsivity and self-regulation. Impulsivity is a strong predictor of problematic smartphone use [55] and problematic smartphone use is a strong predictor of phubbing behavior [6]. Moreover, self-control has been found to be negatively associated with phubbing behavior [7], and while self-control and self-regulation can be used interchangeably, they can also be perceived as distinct processes [56]. Future work should use these same measures to test how robust these findings are.

We created an initial regression model to determine which measure of everyday attentional failures best predicted phubbing behavior. Perceptions of attention-related cognitive errors, or how frequently individuals make minor mistakes as a result of absentmindedness, was the strongest predictor of phubbing behavior. When considering the research on media multitasking and everyday attentional abilities, there are a few possible explanations to infer why phubbing is best predicted by attention-related cognitive errors. Ralph and colleagues [35] explored the deficit-producing hypothesis to determine the extent to which media multitasking predicts poor attentional control. Using causal modeling, media multitasking predicted attention-related cognitive errors, and this effect was mediated by attentional lapses and spontaneous mind wandering. Though we treated attention-related cognitive errors as a predictor variable rather than an outcome variable, Ralph and colleagues' [35] work supports a strong link between this particular attention variable and technology multitasking behaviors such as phubbing, albeit in a different 
manner and with a different behavior. In our initial regression model, difficulty with attentional switching and spontaneous mind wandering were the next biggest predictors of phubbing behavior. When examining these three predictors alongside one another, it appears that individuals who phub may not be entirely aware of that they are engaging in this behavior, and it may be unintentional that they are not focusing all of their attention on the social interaction. Once a "phubber's" attention is captured by a distractor such as their phone, it could be difficult for them to redirect their attention back to the social setting and particularly their conversational partner. Research that integrates an attentional capture paradigm while also measuring phubbing behavior can perhaps further test this inference. Further evaluating Ralph and colleagues' findings [35] brings up the question whether engagement in phubbing behavior can predict attentional failures. We did not explore this possibility because we wanted to remain consistent with most $[8,13,28,29,33,46,55,57]$, though certainly not all $[19,30,35,36,58]$, of past research, which has treated technology use and multitasking behaviors as outcomes and individual differences variables as predictors.

Another finding worth noting is the negative, rather than positive, coefficient for AC-D scores predicting GSP scores in the initial regression model. This implies that, when examined alongside other everyday attentional abilities, reports of lower distractibility predicted a higher phubbing behavior. One potential interpretation could be that because a "phubber's" attention is prioritized toward their phone, they are unlikely to be distracted away from their phone by their conversational partner (rather than be distracted away from their conversational partner by their phone) and this leads to greater phone snubbing behavior. However, this interpretation should be taken with caution given the strong bivariate correlations between our predictor variables, though again multicollinearity was likely not an issue because the VIFs for all predictors in both regression models were below 5 [54]. Replications of our study, as well as perhaps employing a smaller number of measures, could provide more insight.

To account for other potential predictors of phubbing behavior, we expanded our initial regression model to include the six a priori attention predictors in addition to demographics, such as age, and select psychosocial and personality variables, including impulsivity, self-regulation, and social connectedness. The variance in phubbing behavior scores increased from $61 \%$ in the initial regression model to $63 \%$ in the expanded regression model. In this expanded regression model, attention-related cognitive errors remained the biggest predictor of phubbing behavior and was again followed by attentional shifting. Notably, deliberate mind wandering replaced spontaneous mind wandering as the third biggest predictor of phubbing behavior. Though characteristics such as impulsivity, selfregulation, and social connectedness were significantly correlated with phubbing behavior, they were not significant predictors of phubbing behavior. Again, most of the past research on phubbing has used social and personality frameworks. It is surprising that we did not find these select variables to predict phubbing behavior when investigated alongside attention variables. This further emphasizes the importance of investigating phubbing through a cognitive framework. One interpretation of our results could be that attentional abilities can perhaps better explain and predict engagement in this technoference behavior rather than certain personality and psychosocial variables, although more research is needed to verify such a claim. Regardless, our results emphasize the need for future research to further investigate how individual differences in cognitive abilities relate to and predict this technoference behavior.

Our secondary aim was to explore the indirect and direct associations between phubbing and media multitasking. Phubbing and media multitasking both appear to be technology multitasking behaviors, as they involve paying attention to a media activity either while engaging in a social interaction or alongside another media activity. Because these technology use behaviors appear to be conceptually related, exploring the indirect and direct associations among phubbing and media multitasking helped us better understand these different aspects of human-technology interaction. We first investigated the indirect relationship between phubbing and media multitasking by testing if these two behaviors 
shared the same directional relationship among various measures of everyday attentional failures. Consolidating separate pieces of past research has revealed that phubbing and media multitasking are indirectly related among several psychosocial and personality constructs, such as sensation seeking [14,27-29] and fear of missing out $[6,7,13,27]$, and it was possible that a similar trend could be revealed in terms of cognitive abilities, particularly as it concerns attention.

We discovered that phubbing and media multitasking shared the same significant positive associations across all measures of perceived attentional failures. Interestingly, the correlations between phubbing behavior and everyday attentional failures $(r \mathrm{~s}=0.45-0.72)$ were stronger than those observed between media multitasking and everyday attentional failures (for MMI-2, $r \mathrm{~s}=0.27-0.60$; for MMM-S, $r \mathrm{~s}=0.18-0.52$ ). This suggests that attention may be more implicated for phubbing than it is for media multitasking, which could help to explain some of the conflicting findings between media multitasking and self-reported attentional abilities [32-37]. Particularly, some studies have found frequent media multitasking to be associated with impaired reports of task monitoring and switching [32-34], while others have failed to find any such relationship [35]. Another potential explanation of these results could be that phubbing behavior and media multitasking may not require the same attentional abilities. Future studies should explore how various other attentional abilities may be associated with phubbing and media multitasking to better interpret and expand upon our findings. Prior to the current study, the conceptual relatedness and indirect associations between phubbing and media multitasking were not yet proposed. This could possibly be due to the fact that phubbing has been primarily investigated through social and personality frameworks, and media multitasking has been primarily, but not exclusively, investigated from a cognitive framework.

Similarly, we could not find any studies that directly tested for a relationship between phubbing and media multitasking. To address this gap, we examined the correlation between phubbing and media multitasking. We discovered significantly positive correlations between GSP scores and MMI-2 and MMM-S scores. These results imply that individuals who engage in phubbing behavior also frequently media multitask. This further suggests that media multitasking and phubbing are two similar yet distinct manifestations of technology use and multitasking behaviors. Additionally, related to media multitasking, we identified the MMM-S [48] to be a shorter, viable alternative to the original 132-item MMI [25] and modified yet equally lengthy adaptions such as the MMI-2 [46,47] for an adult participant pool sampled from the United States. Prior to our study, it appeared the MMM-S had not been used or validated in a sample of adults located in the United States. Lengthier surveys such as the MMI and MMI-2 could result in low participant motivation that encourages response errors and poor response quality. Identifying shorter, equally valid instrumentation is valuable because it lessens overall study completion time, leaving room to include other measures, and it potentially reduces participant attrition, both of which are especially important for online studies.

Overall, the current study lays the groundwork for future research aimed at better characterizing the relationship between cognitive abilities and various technology use and multitasking behaviors. That said, no study is without limitations, including the current study. For example, using self-report measures allowed us to explore a wide variety of everyday attentional failures as they are associated with, and are predictive of, phubbing behavior. However, we realize that a limitation of self-report measures is that respondents may be influenced by social desirability [59]. Future research interested in expanding upon our findings could use cognitive behavioral tasks to better clarify and tease apart such relationships. Specifically, while we found self-reported task switching ability to be strongly correlated with and predictive of phubbing behavior, it is not clear if these patterns would be similar should future studies use reaction time measures of task switching performance. Another limitation is our conceptualization of multitasking primarily as task switching in the current study. Task switching is just one multitasking domain. Dual task ability involves simultaneously attending to two or more sources of information or tasks at a given time, 
while selective attention refers to the ability to attend to certain information or tasks while ignoring, or attempting to ignore, competing irrelevant information or tasks $[17,23,24]$. Switching attention (i.e., task switching), divided attention (i.e., dual task), and selective attention are often used interchangeably, though these attentional domains are distinct from one another $[17,23,24]$. Coincidingly exploring switching, divided, and selective attentional performance-based abilities alongside self-reported technoference behavior could underpin the exact attentional domains associated with such technology use and multitasking behaviors. Continuing this line of research can inform future inventions that aim to reduce the negative impact of such technology use and multitasking behaviors.

Author Contributions: Conceptualization, K.S.S. and N.W.; methodology, K.S.S.; software, N.W.; validation, K.S.S.; formal analysis, K.S.S. and N.W.; investigation, K.S.S.; resources, N.W.; data curation, K.S.S. and N.W.; writing-original draft preparation, K.S.S.; writing-review and editing, K.S.S. and N.W.; visualization, K.S.S. and N.W.; supervision, K.S.S. and N.W.; project administration, K.S.S. and N.W. All authors have read and agreed to the published version of the manuscript.

Funding: This research did not receive any specific grant from funding agencies in the public, commercial, or not-for-profit sectors.

Institutional Review Board Statement: The study was conducted according to the guidelines of the Declaration of Helsinki and approved by the Institutional Review Board of Tufts University (protocol code: \#00000926; date of approval: 20 August 2020).

Informed Consent Statement: Informed consent was obtained from all subjects involved in the study.

Data Availability Statement: The de-identified data presented in this study are openly available on the Open Science Framework at https:/ / osf.io/7kgnd/ (accessed on 12 April 2021).

Acknowledgments: The authors would like to thank Sidney Peach for their crucial role in facilitating project management, administration, and supervision, as well as Sara Siquiera and Andrew Vittiglio for their assistance with data curation.

Conflicts of Interest: The authors declare no conflict of interest.

\section{References}

1. Vogels, E.; Perrin, A.; Rainie, L.; Anderson, M. 53\% of Americans Say the Internet Has Been Essential during the COVID-19 Outbreak. Available online: https://www.pewresearch.org/internet/wp-content/uploads/sites/9/2020/04/PI_2020.04.30 _COVID-internet_REPORT.pdf (accessed on 1 October 2020).

2. Rainie, L.; Zickuhr, K. Americans' Views on Mobile Etiquette. Available online: https://www.pewresearch.org/internet/2015/0 8/26/americans-views-on-mobile-etiquette/ (accessed on 1 October 2020).

3. McDaniel, B.T.; Drouin, M. Daily technology interruptions and emotional and relational well-being. Comput. Hum. Behav. 2019, 99, 1-8. [CrossRef]

4. McDaniel, B.T.; Galovan, A.M.; Cravens, J.D.; Drouin, M. “Technoference” and implications for mothers' and fathers' couple and coparenting relationship quality. Comput. Hum. Behav. 2018, 80, 303-313. [CrossRef]

5. McDaniel, B.T.; Coyne, S.M. "Technoference": The interference of technology in couple relationships and implications for women's personal and relational well-being. Psychol. Pop. Media Cult. 2016, 5, 85-98. [CrossRef]

6. Chotpitayasunondh, V.; Douglas, K.M. How "phubbing" becomes the norm: The antecedents and consequences of snubbing via smartphone. Comput. Hum. Behav. 2016, 63, 9-18. [CrossRef]

7. Chotpitayasunondh, V.; Douglas, K.M. Measuring phone snubbing behavior: Development and validation of the Generic Scale of Phubbing (GSP) and the Generic Scale of Being Phubbed (GSBP). Comput. Hum. Behav. 2018, 88, 5-17. [CrossRef]

8. Karadă̆, E.; Tosuntaş, Ş.B.; Erzen, E.; Duru, P.; Bostan, N.; Şahin, B.M.; Çulha, İ.; Babadă̆, B. Determinants of phubbing, which is the sum of many virtual addictions: A structural equation model. J. Behav. Addict. 2015, 4, 60-74. [CrossRef] [PubMed]

9. Karadă̆, E.; Tosuntaş, Ş.B.; Erzen, E.; Duru, P.; Bostan, N.; Mizrak Şahin, B.; Çulha, İ.; Babadă̆, B. The virtual world's current addiction: Phubbing. Addicta 2016, 3. [CrossRef]

10. Al-Saggaf, Y.; O’Donnell, S.B. Phubbing: Perceptions, reasons behind, predictors, and impacts. Hum. Behav. Emerg. Technol. 2019, 1, 132-140. [CrossRef]

11. Al-Saggaf, Y.; MacCulloch, R. Phubbing: How frequent? who is phubbed? in which situation? and using which apps? In Proceedings of the 39th International Conference on Information Systems (ICIS), Association for Information Systems, Marriott Marquis, San Francisco, CA, USA, 13-16 December 2018.

12. Erzen, E.; Odaci, H.; Yeniçeri, İ. Phubbing: Which personality traits are prone to phubbing? Soc. Sci. Comput. Rev. 2019, 1-14. [CrossRef] 
13. Balta, S.; Emirtekin, E.; Kircaburun, K.; Griffiths, M.D. Neuroticism, trait fear of missing out, and phubbing: The mediating role of state fear of missing out and problematic Instagram use. Int. J. Ment. Health Addict. 2020, 18, 628-639. [CrossRef]

14. Schneider, F.M.; Hitzfeld, S. I ought to put down that phone but I phub nevertheless: Examining the predictors of phubbing behavior. Soc. Sci. Comput. Rev. 2019, 1-14. [CrossRef]

15. Wilmer, H.H.; Chein, J.M. Mobile technology habits: Patterns of association among device usage, intertemporal preference, impulse control, and reward sensitivity. Psychon. Bull. Rev. 2016, 23, 1607-1614. [CrossRef]

16. Wilmer, H.H.; Sherman, L.E.; Chein, J.M. Smartphones and cognition: A review of research exploring the links between mobile technology habits and cognitive functioning. Front. Psychol. 2017, 8, 1-16. [CrossRef]

17. Liebherr, M.; Schubert, P.; Antons, S.; Montag, C.; Brand, M. Smartphones and attention, curse or blessing?-A review on the effects of smartphone usage on attention, inhibition, and working memory. Comput. Hum. Behav. Rep. 2020, 1, 1-8. [CrossRef]

18. Frost, P.; Donahue, P.; Goeben, K.; Connor, M.; Cheong, H.S.; Schroeder, A. An examination of the potential lingering effects of smartphone use on cognition. Appl. Cognit. Psychol. 2019, 33, 1055-1067. [CrossRef]

19. Marty-Dugas, J.; Ralph, B.C.W.; Oakman, J.M.; Smilek, D. The relation between smartphone use and everyday inattention. Psychol. Conscious. Theory Res. Pract. 2018, 5, 46-62. [CrossRef]

20. Abramova, O.; Baumann, A.; Krasnova, H.; Lessmann, S. To phub or not to phub: Understanding off-task smartphone usage and its consequences in the academic environment. In Proceedings of the 25th European Conference on Information Systems (ECIS), Guimarães, Portugal, 5-10 June 2017; pp. 1984-1999.

21. Amichai-Hamburger, Y.; Shir, E. Intimacy and smartphone multitasking-A new oxymoron? Psychol. Rep. 2016, 119. [CrossRef] [PubMed]

22. Yang, C.; Christofferson, K. On the phone when we're hanging out: Digital social multitasking (DSMT) and its socioemotional implications. J. Youth Adolesc. 2020, 49, 1209-1224. [CrossRef]

23. Koch, I.; Poljac, E.; Müller, H.; Kiesel, A. Cognitive structure, flexibility, and plasticity in human multitasking-An integrative review of dual-task and task-switching research. Psychol. Bull. 2018, 144, 557-583. [CrossRef]

24. Ward, N.; Hussey, E.K.; Cunningham, E.C.; Paul, E.J.; McWilliams, T.; Kramer, A.F. Building the multitasking brain: An integrated perspective on functional brain activation during task-switching and dual-tasking. Neuropsychologia 2019, 132, 107149. [CrossRef]

25. Ophir, E.; Nass, C.; Wagner, A.D. Cognitive control in media multitaskers. Proc. Natl. Acad. Sci. USA 2009, 106, 15583-15587. [CrossRef] [PubMed]

26. Segijn, C.M.; Xiong, S.; Duff, B.R.L. Manipulating and measuring media multitasking: Implications of previous research and guidelines for future research. Commun. Methods Meas. 2019, 13, 83-101. [CrossRef]

27. Duff, B.; Yoon, G.; Wang, Z.; Anghelcev, G. Doing it all: An exploratory study of predictors of media multitasking. J. Interact. Advert. 2014, 14, 11-23. [CrossRef]

28. Sanbonmatsu, D.M.; Strayer, D.L.; Medeiros-Ward, N.; Watson, J.M. Who multi-tasks and why? Multi-tasking ability, perceived multi-tasking ability, impulsivity, and sensation seeking. PLoS ONE 2013, 8, e54402. [CrossRef] [PubMed]

29. Luo, J.; Liang, L. Exploring the relationships among university students' media multitasking, personality and academic performance: A quantitative study. In Proceedings of the International Scientific Conference: Lodging the Theory in Social and Educational Practice, Vladivostok, Russia, 25-27 April 2018; pp. 1-10.

30. Becker, M.; Alzahabi, R.; Hopwood, C. Media multitasking is associated with symptoms of depression and social anxiety. Cyberpsychol. Behav. Soc. Netw. 2012, 16, 1-5. [CrossRef]

31. Wang, Z.; Tchernev, J.M. The "myth" of media multitasking: Reciprocal dynamics of media multitasking, personal needs, and gratifications. J. Commun. 2012, 62, 493-513. [CrossRef]

32. Magen, $\mathrm{H}$. The relations between executive functions, media multitasking and polychronicity. Comput. Hum. Behav. 2017, 67, 1-9. [CrossRef]

33. Baumgartner, S.E.; Weeda, W.D.; van der Heijden, L.L.; Huizinga, M. The relationship between media multitasking and executive function in early adolescents. J. Early Adolesc. 2014, 34, 1120-1144. [CrossRef]

34. Wiradhany, W.; Koerts, J. Everyday functioning-related cognitive correlates of media multitasking: A mini meta-analysis. Media Psychol. 2019, 1-28. [CrossRef]

35. Ralph, B.C.W.; Thomson, D.R.; Cheyne, J.A.; Smilek, D. Media multitasking and failures of attention in everyday life. Psychol. Res. 2014, 78, 661-669. [CrossRef]

36. Yildirim, C.; Dark, V.J. The mediating role of mindfulness in the relationship between media multitasking and mind wandering. In Proceedings of the Technology, Mind, and Society; ACM Press: Washington, DC, USA, 2018; pp. 1-5.

37. Irwin, M.L. The Dynamics of Media Use, Attention, and Behavioral Control. Ph.D. Thesis, The Ohio State University, Colombus, $\mathrm{OH}, \mathrm{USA}, 2017$.

38. Peer, E.; Vosgerau, J.; Acquisti, A. Reputation as a sufficient condition for data quality on amazon Mechanical Turk. Behav. Res. 2014, 46, 1023-1031. [CrossRef]

39. Schönbrodt, F.D.; Perugini, M. At what sample size do correlations stabilize? J. Res. Personal. 2013, 47, 609-612. [CrossRef]

40. Tabachnick, B.L.; Fidell, L.S. Using Multivariate Statistics, 6th ed.; Pearson Education: Boston, MA, USA, 2012; ISBN 0-205-84957-1.

41. Carriere, J.S.A.; Seli, P.; Smilek, D. Wandering in both mind and body: Individual differences in mind wandering and inattention predict fidgeting. Can. J. Exp. Psychol.Rev. Can. Psychol. Expérimentale 2013, 67, 19-31. [CrossRef] 
42. Derryberry, D.; Reed, M.A. Anxiety-related attentional biases and their regulation by attentional control. J. Abnorm. Psychol. 2002, 111, 225-236. [CrossRef]

43. Carriere, J.S.A.; Cheyne, J.A.; Smilek, D. Everyday attention lapses and memory failures: The affective consequences of mindlessness. Conscious. Cogn. 2008, 17, 835-847. [CrossRef]

44. Brown, K.W.; Ryan, R.M. The benefits of being present: Mindfulness and its role in psychological well-being. J. Pers. Soc. Psychol. 2003, 84, 822-848. [CrossRef] [PubMed]

45. Cheyne, J.A.; Carriere, J.S.A.; Smilek, D. Absent-mindedness: Lapses of conscious awareness and everyday cognitive failures. Conscious. Cogn. 2006, 15, 578-592. [CrossRef]

46. Ralph, B.C.W.; Thomson, D.R.; Carriere, J.S.; Smilek, D. Media multitasking and behavioral measures of sustained attention. Atten. Percept. Psychophys. 2015, 77, 390-401. [CrossRef] [PubMed]

47. Ralph, B.C.W.; Smilek, D. Individual differences in media multitasking and performance on the N-Back. Atten. Percept. Psychophys. 2017, 79, 582-592. [CrossRef]

48. Baumgartner, S.E.; Lemmens, J.S.; Weeda, W.D.; Huizinga, M. Measuring media multitasking: Development of a short measure of media multitasking for adolescents. J. Media Psychol. 2017, 29, 1-10. [CrossRef]

49. Patton, J.H.; Stanford, M.S.; Barratt, E.S. Factor structure of the Barratt Impulsiveness Scale. J. Clin. Psychol. 1995, 51, 768-774. [CrossRef]

50. Carey, K.B.; Neal, D.J.; Collins, S.E. A psychometric analysis of the Self-Regulation Questionnaire. Addict. Behav. 2004, 29, 253-260. [CrossRef] [PubMed]

51. Brown, J.M.; Miller, W.R.; Lawendowski, L.A. The Self-Regulation Questionnaire. In Innovations in Clinical Practice: A Source Book; Professional Resource Press/Professional Resource Exchange: Sarasota, FL, USA, 1999; Volume 17, pp. $281-292$.

52. Lee, R.M.; Robbins, S.B. Measuring belongingness: The Social Connectedness and the Social Assurance Scales. J. Couns. Psychol. 1995, 42, 232-241. [CrossRef]

53. Hauser, D.J.; Schwarz, N. Attentive Turkers: MTurk Participants perform better on online attention checks than do subject pool participants. Behav. Res. 2016, 48, 400-407. [CrossRef]

54. Keith, T.Z. Multiple Regression and Beyond: An Introduction to Multiple Regression and Structural Equation Modeling, 3rd ed.; Routledge: New York, NY, USA, 2019; ISBN 978-1-138-06142-2.

55. Billieux, J.; Van der Linden, M.; Rochat, L. The role of impulsivity in actual and problematic use of the mobile phone. Appl. Cognit. Psychol. 2008, 22, 1195-1210. [CrossRef]

56. Nigg, J.T. Annual Research Review: On the relations among self-regulation, self-control, executive functioning, effortful control, cognitive control, impulsivity, risk-taking, and inhibition for developmental psychopathology. J Child Psychol. Psychiatr. 2017, 58, 361-383. [CrossRef] [PubMed]

57. Rogobete, D.A.; Ionescu, T.; Miclea, M. The relationship between media multitasking behavior and executive function in adolescence: A replication study. J. Early Adolesc. 2020, 1-29. [CrossRef]

58. Murphy, K.; Creux, O. Examining the association between media multitasking, and performance on working memory and inhibition tasks. Comput. Hum. Behav. 2021, 114, 1-11. [CrossRef]

59. Furnham, A. Response bias, social desirability and dissimulation. Personal. Ind. Diff. 1986, 7, 385-400. [CrossRef] 